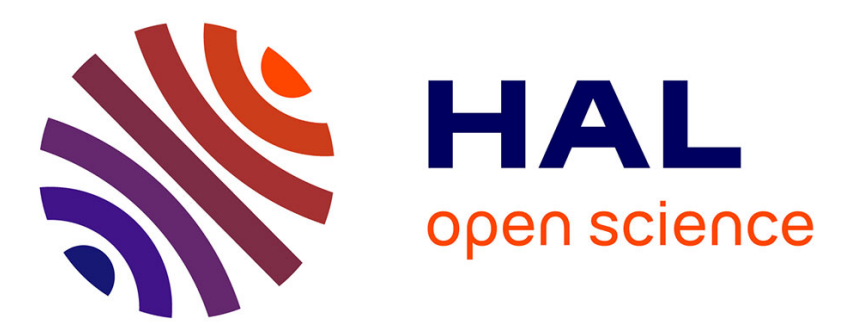

\title{
WAVELENGTH SCALING OF LITHIUM-LIKE RECOMBINATION SCHEME FOR X-UV GAIN PRODUCTION
}

\author{
A. Carillon, F. Gadi, B. Gauthé, H. Guennou, P. Jaeglé, G. Jamelot, A. \\ Klisnick, C. Möller, A. Sureau
}

\section{To cite this version:}

A. Carillon, F. Gadi, B. Gauthé, H. Guennou, P. Jaeglé, et al.. WAVELENGTH SCALING OF LITHIUM-LIKE RECOMBINATION SCHEME FOR X-UV GAIN PRODUCTION. Journal de Physique Colloques, 1987, 48 (C9), pp.C9-375-C9-378. 10.1051/jphyscol:1987966 . jpa-00227384

\section{HAL Id: jpa-00227384 https://hal.science/jpa-00227384}

Submitted on 1 Jan 1987

HAL is a multi-disciplinary open access archive for the deposit and dissemination of scientific research documents, whether they are published or not. The documents may come from teaching and research institutions in France or abroad, or from public or private research centers.
L'archive ouverte pluridisciplinaire HAL, est destinée au dépôt et à la diffusion de documents scientifiques de niveau recherche, publiés ou non, émanant des établissements d'enseignement et de recherche français ou étrangers, des laboratoires publics ou privés. 


\title{
WAVELENGTH SCALING OF LITHIUM-LIKE RECOMBINATION SCHEME FOR X-UV GAIN PRODUCTION
}

\author{
A. CARILLON, F. GADI, B. GAUTHE, H. GUENNOU, P. JAEGLE, \\ G. JAMELOT, A. KLISNICK, C. MÖLLER and A. SUREAU \\ Laboratoire de Spectroscopie Atomique et Ionique, Bât. 350 , \\ Université Paris-Sud, F-91405 Orsay Cedex, France \\ and GILM, Ecole Polytechnique, F-91128 palaiseau cedex, France
}

RESUME. On présente des valeurs de gain obtenues tant par mesures expérimentales que par prévisions théoriques pour les transitions $3 d-5 f, 3 d-4 f$ et $4 d-5 f$ des ions lithiumö̈des dans des plasmas produits par laser. A la suite d'une étude détaillée du cas de 1 ion $A 1$ 10+/1/ et en se fondant sur des prévisions obtenues par calcul pour les ions de charge plus élevée $1 / 2 /$, nous présentons les premiers résultats expérimentaux concernant les ions $\mathrm{s}^{1+}$. En particulier, un coefficient de gain de 1 'ordre de $1 \mathrm{~cm}^{-1}$ a été mesuré pour la transition $3 \mathrm{~d}-5 \mathrm{f}$ de $\mathrm{S}$ XIV à la longueur d'onde de $65.2 \AA$, qui est la plus courte pour laquelle la mesure d'un gain ait jamais fajt l'objet d'une publication jusqu'à ce jour. Des calculs concernant les ions $\mathrm{K}$, $\mathrm{Ca}$ et $\mathrm{Ti} \mathrm{I}^{\mathrm{I}+}$ sont également présentés.

ABSTRACT. Observed and predicted values of gain for $3 d-5 f, 3 d-4 f$ and $4 d-5 f$ transitions of lithium-like ions in laser-produced plasmas are reported. After an extensive study of the $\mathrm{Al}^{10^{+}}$case $/ 1 /$ and following calculated predictions for higher- $Z$ ions $/ 2 /$ we present the first experimental results concerning the $s$ ion. In particular, a gain coefficient of the order of $1 \mathrm{~cm}$ has been measured for the $3 d-5 f$ transition of $S$ XIV at the wavelength of $65.2 \AA$, which is the shortest for which the measurement $9 f+^{a}$ gain ${ }^{\text {gat }}$ ever been published to day. Some calculations concerning the $\mathrm{K}^{16+}, \mathrm{Ca}{ }^{9}$ and $\mathrm{Ti}{ }^{19+}$ ions are also presented.

INTRODUCTION. Although no X-ray laser device has yet been achieved to day, the most recent progress in this field /3/ has made it sure such a feasibility. As a consequence of that, the preoccupation of searchers is no more only to increase the value of the gain-length product they obtain in their experiments, but also to look forward for future applications. Among these, the interest of biologists for shorter wavelengths comprised between 23.3 and $43.5 \mathrm{~A}$, in the so-called water-window, is now well known. In this range, since water is rather transparent to radiation while carbon is opaque, one can hope to obtain holograms of living proteins with a good contrast. That is one of the reasons why wavelength-scaling of the different schemes considered for $X-r a y$ lasing action has become an increasing preoccupation.

PRESENTATION. In this pgper we shall deal with lithium-like recombination scheme, departing from the Al ${ }^{4}$ case for which we have reported an amplification of spontaneous emission at $105.7 \AA$ as early as $1978 / 4 /$. Indeed, if one considers these ions in a rapidly cooling plasma, population inversion appears between the lower $3 d$ level and the upper $4 f(154.6 \AA)$ and $5 f$ levels (105.7 $\AA$ ) as predicted by calculation taking into account radiative cascades and collisionnal transitions rates $/ 2,5,6 /$. Experimental gain measurements have been performed for both transitions, in the corona, $i . e .$, in a region of the laser-produced plasma where electronic density $N$

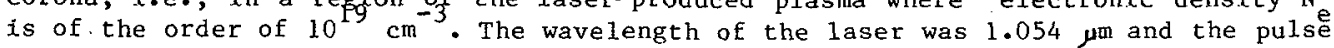
duration was either 600 ps or 2 ns. The laser bean was focused on the surface of a massive target by two crossed cylindrical lenses, providing a fairly homogeneous lighting along the focal line of 1 to $2 \mathrm{~cm}$ long. The flux linear density on the target was in the range of 0.5 to $20 \mathrm{GW} / \mathrm{cm}$. Gain $\mathrm{G}$ was deduced from the enhancement of emitted intensity $I_{1}$ with plasma length 1 using the relation $I_{1} \propto \exp (G 1)-1$. Time-resolved experiments have shown that amplification takes place during plasma 
cooling after the top of the laser pulge. Measured peak values of gain-length product are comprised between 2 and $2.5 \mathrm{~cm}^{-1}$. These results have been accounted for by theoretical calculations which have shown that, in the case of aluminium, gain occurs for the $5 \mathrm{f}-3 \mathrm{~d}$ and $4 \mathrm{f}-3 \mathrm{~d}$ transitions in the plasma corona during the cooling and recombination phase. Calculations are performed with a collisionnal-radiative model used as the postprocessor of a hydrodynamical code.

Considering a higher 2 element as sulphur, for which the $3 d-5 f$ and $3 d-4 f$ transitions of SXIV are situated at 65.2 and $95.5 \AA$, the $C . R$. model has been used introducing various sets of density and temperature obtained from the hydrodynamical code in the case of Al. This is made possible by the rather broad range of convenient values revealed by the code. The $C . R$. model gives the values of inversion density $\Delta n$ and, since the expression of gain is given by:

$$
G\left(\mathrm{~cm}^{-1}\right)=3.27410^{-1 / 4}(\Delta \mathrm{n}) \mathrm{S}(\mathrm{M} / \mathrm{kTi})^{1 / 2}
$$

where $n$ is expressed in $\mathrm{cm}^{-3}, \mathrm{~S}$ is the line strength in u.a., M the atomic mass and $T i$ the ionic temperature in $\mathrm{eV}$, one can obtain the expected value of gain in each case. Table I shows a comparison of representative results obtained for Al and $S$. It appears that comparable values of gain can be obtained with both elements.

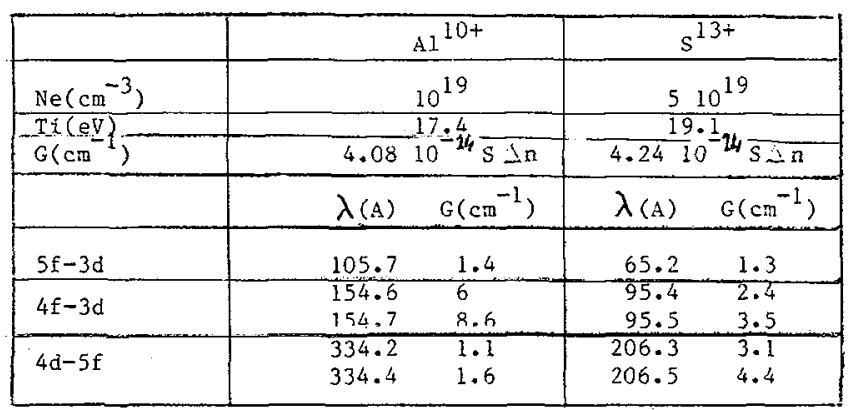

T A B L E I

On the basis of this evaluation a study of the 5f-3d transition in sulphur, at $65.2 \AA$, has been undertaken. A massive planar target was used and we compared intensities emitted by plasmas of 1 and $2 \mathrm{~cm}$ produced by a $1.054 \mu \mathrm{m}-150 \mathrm{~J} 1 \mathrm{~s}$ er beam with a pulse duration of 2 ns. The lm-grazing incidence spectrometer uses a 3,600 grooves $/ \mathrm{mm}$ grating. An 0.M.A. Was used for detection. For this first experiment only time-integrated measurements were made. An example of result is shown on Fig. 1 . Upper curves represent the spectra emitted by both plasmas in the region of $65 \AA$. The strongest 1ine is the $5 \mathrm{f}-3 \mathrm{~d}$ at $65.2 \AA$, while the other one on the left side is the $5 \mathrm{~d}-3 \mathrm{p}$ at $64.3 \AA$. At $65.2 \AA$, a sudden drop is clearly visible in the absorption curve which is represented in lower part.

A simulation has been undertaken to investigate the effects of time-integration on the observed value of gain as well as those of the experimental width. The result of this study, as it appears in Fig.2 and 3 , shows that an instant gain of about $1 \mathrm{~cm}^{-1}$ accounts for the experimental observations.

WAVELENGTH SCALING. When scaling with higher Z-elements towards shorter wavelengths one must consider laser intensity, electronic density and electronic temperature. In the Li-like recombination scheme, laser intensity must be sufficient for creating He-like ions. Since the presence of these ions is conditionning the inversion scheme, if $Z$ is the atomic number of an element, the scaling will depend not on $Z$ but on the parameter $z=Z-2$. So, with an element $Z^{\prime}$, let $z^{\prime}=Z^{\prime}-2$, the following relations have to be considered:

$$
\begin{aligned}
& I^{\prime} \text { laser }=\left(z^{\prime} / z\right)^{3} I_{\text {laser }} \\
& \mathrm{N}_{\mathrm{e}}{ }^{\prime}=\left(\mathrm{z}^{*} / \mathrm{z}\right)^{7} \mathrm{~N}_{\mathrm{e}} \\
& \mathrm{T}_{\mathrm{e}}^{\prime}=\left(\mathrm{z}^{\prime} / \mathrm{z}\right)^{2} \mathrm{~T}_{\mathrm{e}}
\end{aligned}
$$



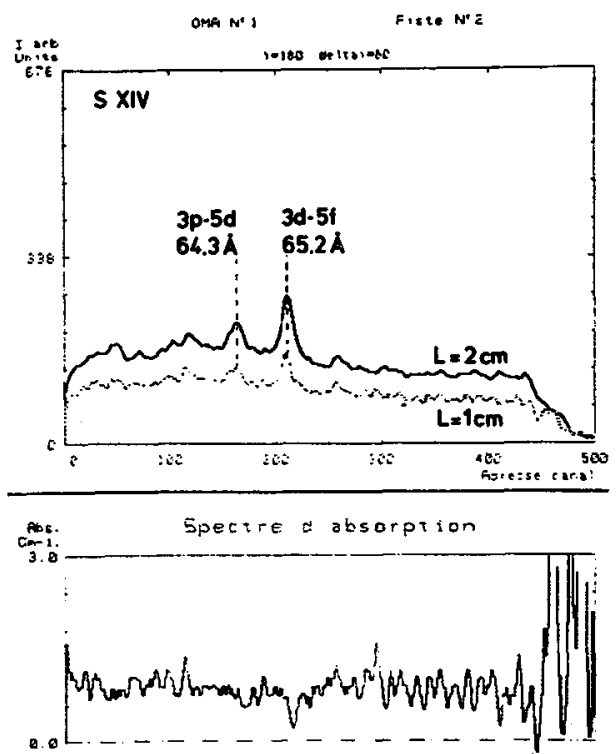

Experimental result in sulphur. Lower part: absorption curve. Fig. 1

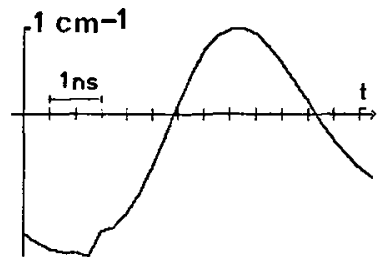

Time-resolved gain at the top of the line deduced from a plasma modeling Fig. 2
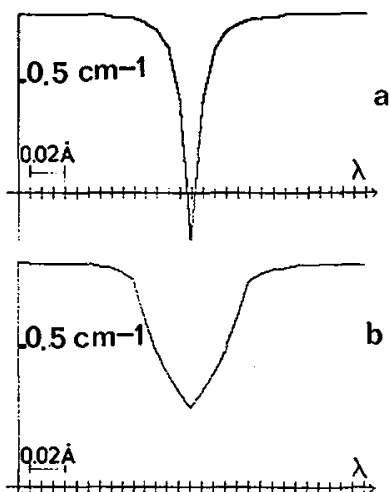

Time-integrated absorption curve a) directly deduced from gain in Fig. 2 b) taking into account instrumental width

Fig. 3

On the basis of this scaling, departing from sulphur, a theoretical study has been undertaken concerning $\mathrm{Ca}, \mathrm{T} i$ and $\mathrm{Cu} / 7 /$. Calculated wavelengths in Ångström of $3 \mathrm{~d}-4 \mathrm{f}$, $3 d-5 f, 4 d-5 f$ and $4 f-5 g$ transitions are the following:

$\begin{array}{lrrr} & \mathrm{Ca} 17+ & \mathrm{Ti} & \mathrm{Cu}^{26+} \\ 3 \mathrm{~d} 3 / 2-5 f 5 / 2 & 39.50 & 31.99 & 17.54 \\ 3 \mathrm{~d} 5 / 2-5 f 7 / 2 & 39,55 & 32,04 & 17.59 \\ 3 \mathrm{~d} 3 / 2-4 f 5 / 2 & 57.76 & 46.77 & 25.64 \\ 3 \mathrm{~d} 5 / 2-4 \mathrm{f} 7 / 2 & 57.86 & 46.87 & 25.74 \\ 4 \mathrm{~d} 3 / 2-5 f 5 / 2 & 124.78 & 101.06 & 55.41 \\ 4 \mathrm{f} 5 / 2-5 \mathrm{~g} 7 / 2 & 124.95 & 101.20 & 55.50 \\ 4 \mathrm{~d} 5 / 2-5 \mathrm{f} 7 / 2 & 124.97 & 101.25 & 55.59 \\ 4 \mathrm{f} 7 / 2-5 \mathrm{~g} 9 / 2 & 125.03 & 101.29 & 55.59\end{array}$

Extrapolated plasma parameters have been introduced into the time-dependent C.R. mode1. Energy levels and oscillator strengths used in the model are obtained by ab initio calculations with a modified Hartree-Fock method. Atomic dynamics includes radiative cascades and electron-ion collisions. Reduced-population densities $\mathrm{N} / \mathrm{g}$, where $g=2 j+1$ is the statistical weight of the level, have been calculated as functions of temperature $T_{f}$. This was performed for different values of $N_{e}$ and in each case, for various values of the parameter $X$ which represents the proportion of He-like to Li-like ions. On Fig.4 are presented the most characteristic results obtained for both $5 \mathrm{f}-3 \mathrm{~d}$ and $4 \mathrm{f}-3 \mathrm{~d}$ transitions. It appears that in all cases 
significative inversion-ratio values are obtained. Due to lack of space, 5-4 transitions are not presented here although still stronger values have been observed in some cases. Thus, these results demonstrate the interesting possibilities offered by $L i-1 i k e$ ions in $X-U V$ laser studies.
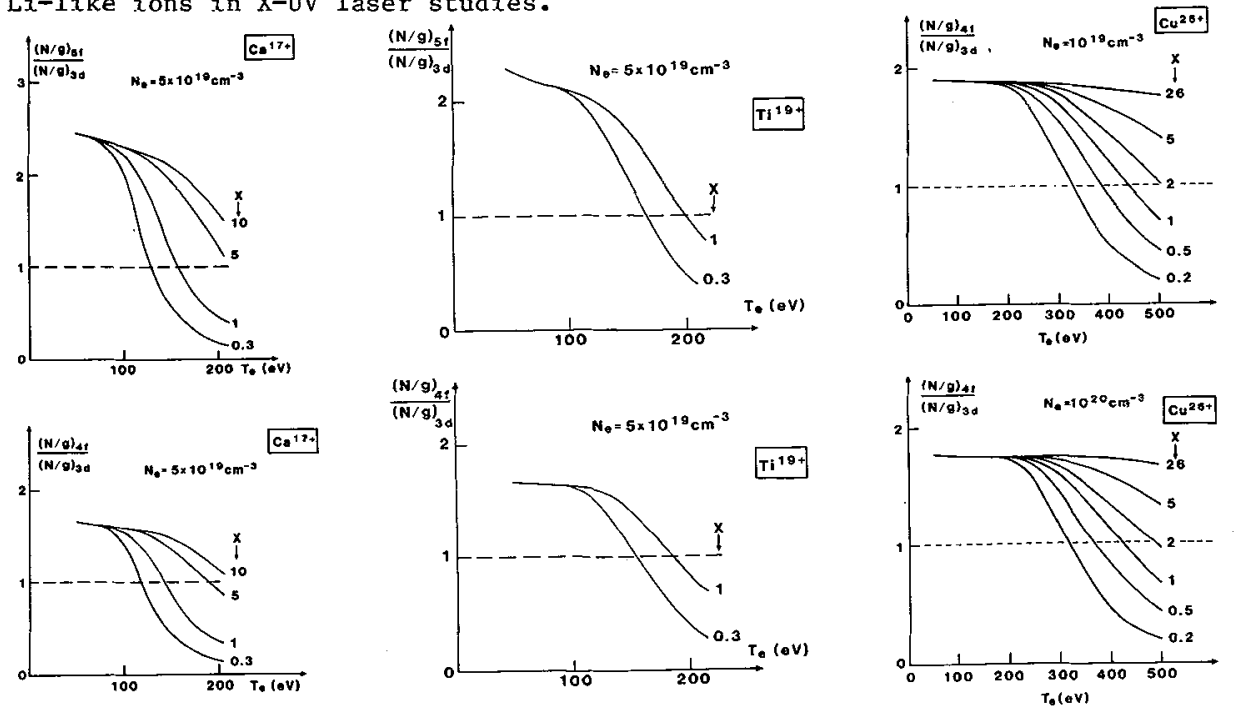

Fig. 4

CONCLUSION. Li-ijke recombination scheme seems particularly appropriate for scaling towards shorter wavelengths since the need in power density for plasma production is rather moderate. An illustration of that is represented in $\mathrm{Fig} .5$ where we have plotted power densities versus wavelengths for the different schemes proposed to-day. Another aspect of this study is to show up the interest of investigating also the 4-5 transitions, particularly the $4 d-5 f$ and $4 f-5 g$, not for shorter wavelengths, but for higher gains.

\section{REFERENCES}

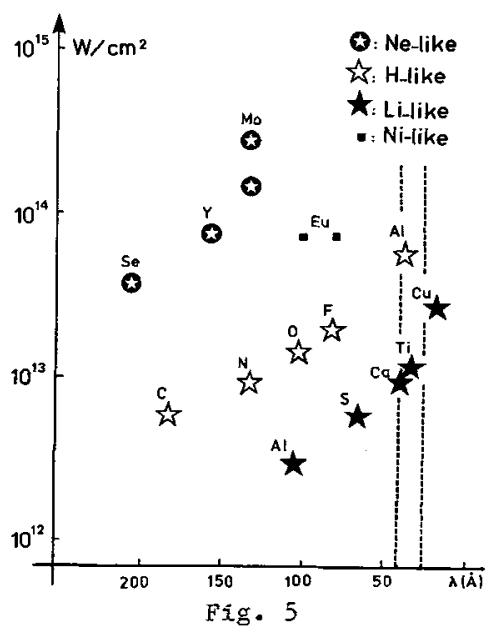

/1/ - P. JAEGLE, G. JAMELOT, A. CARILLON, A. KLISNICK, A. SUREAU and H. GUENNOU, J.O.S.A. B, 4, 563 (1987); (Feature edition on the Generation of Coherent XUV and Soft-X-ray Radiation).

/2/ - H. GUENNOU, A. SUREAU, C. MOLLER, International Colloquium on X-Ray Lasers, Aussois, France, 1986; Journal de physique, C6-351, Vol 47 (1986).

/3/ - D.L. MATTHEWS et al., Phys. Rev. Lett, 54, 110 (1985).

14 - P. JAEGLE, G. JAMELOT, A. CARILLON and C. WEHENKEL, Jpn. J. Appl. Phys. 17, $483(1978)$.

/5/ - A. KLISNICK, H. GUENNOU and J. VIRMONT, Journal de Physique, 47, C6 351 (1986).

$16 /$ - H. GUENNOU and A. SUREAU, J. Phys. B, 20, 919 (1987).

$/ 7 /$ - A. SUREAU, H. GUENNOU, C. MOLLER. Proceedings of the I.U.A. colloquium $\mathrm{N}^{\circ} 102$, September 9-11 September 1987, Beaulieu s/mer, France. 